\title{
Configurações
}

Revista de sociologia

$24 \mid 2019$

Imaginar "futuros" do trabalho, contextos e vivências subjetivas

\section{Futureal: crime e tecnologias convergentes em Psycho-Pass}

Futureal: crime and converging technologies in Psycho-Pass

Crime et technologies convergentes dans Psycho-Pass

\section{Sílvia Gomes e Rui Vieira Cruz}

\section{OpenEdition \\ Journals}

\section{Edição electrónica}

URL: http://journals.openedition.org/configuracoes/7802

DOI: $10.4000 /$ configuracoes.7802

ISSN: 2182-7419

\section{Editora}

Centro de Investigação em Ciências Sociais

\section{Edição impressa}

Paginação: 96-121

ISSN: 1646-5075

\section{Refêrencia eletrónica}

Sílvia Gomes e Rui Vieira Cruz, "Futureal: crime e tecnologias convergentes em Psycho-Pass », Configurações [Online], 24 | 2019, posto online no dia 18 dezembro 2019, consultado o 19 dezembro 2019. URL : http://journals.openedition.org/configuracoes/7802 ; DOI : 10.4000/configuracoes.7802 
Gomes, Sílvia; Cruz, Rui Vieira - Futureal: crime e tecnologias convergentes em Psycho-Pass. Configurações, vol. 24, 2018, pp. 96-121.

\title{
Futureal: crime e tecnologias convergentes em Psycho-Pass
}

\author{
SÍLVIA GOMES * \\ Centro Interdisciplinar de Ciências Sociais - Pólo UMinho e Florida State University \\ RUI VIEIRA CRUZ ** \\ Centro Interdisciplinar de Ciências Sociais - Pólo UMinho e Centro de Estudos de Comunicação e Sociedade \\ da Universidade do Minho
}

\section{Resumo}

Este artigo constitui-se como um exercício de reflexão sobre a forma de aplicação de diferentes tecnologias no controlo formal das práticas criminais e como aquelas acabam por transformar uma organização societal e as concepções desta sobre o que é o crime e, consequentemente, o criminoso. Esta reflexão é realizada a partir da análise da primeira temporada do anime cyberpunk japonês Psycho-Pass, centrado em torno do tema do combate ao crime num futuro distópico. Seguindo o potencial das tecnologias convergentes e os princípios da life course criminology, descrevemos como são enquadradas as diferentes tecnologias na construção de elementos de dissuasão criminal, exploramos mecanismos de controlo social formal desenvolvidos e aplicados pelos seus agentes sociais, refletimos em torno das reconfigurações sociais do que é o crime e o criminoso e identificamos o tipo de fatores que são avançados para a explicação do envolvimento criminal dos indivíduos.

Palavras-chave: Psycho-Pass; cyberpunk; tecnologias convergentes; life course criminology.

\footnotetext{
Abstract

Futureal: crime and converging technologies in Psycho-Pass

This article is a reflective exercise on the application of different technologies in the formal control of criminal practices and how they end up transforming a societal organisation and its conceptions regarding the crime and, consequently, the criminal. This reflection is based on the analysis of the first season of the Japanese cyberpunk anime Psycho-Pass, centred on the theme of fighting crime in a dystopian future. Following the potential of technological convergence and the principles of life course criminology,

${ }^{\star}$ E-mail: silvia.gomes@ics.uminho.pt.

**E-mail: rmvcruz@gmail.com.
} 
we (i) describe how different technologies are framed in the construction of elements of criminal deterrence; (ii) explore the mechanisms of formal social control developed and applied by its social agents; (iii) reflect on the social reconfigurations of both crime and the criminal; and (iv) identify the kinds of factors that are used to explain criminal practice.

Keywords: Psycho-Pass; cyberpunk; converging technologies; life course criminology.

\section{Resumé}

\section{Crime et technologies convergentes dans Psycho-Pass}

Cet article est un exercice de réflexion sur la façon d'appliquer différentes technologies au contrôle formel des pratiques criminelles et la façon dont celles-ci finissent par transformer une organisation sociétale et les conceptions de celle-ci sur ce qu'est le crime et, par conséquent, le criminel. Cette réflexion est faite à partir de l'analyse de la première saison de l'anime cyberpunk japonais Psycho-Pass, centré sur le thème de la lutte contre la criminalité dans un futur dystopique. D'après le potentiel des technologies convergentes et les principes de la life-course criminology, nous décrivons comment sont encadrées les différentes technologies dans la construction des éléments de dissuasion criminels, explorons les mécanismes de contrôle officiels développés et appliqués par leurs travailleurs sociaux, réfléchissons sur les reconfigurations sociales de ce qu'est le crime et le criminel et identifions le type de facteurs qui sont avancés pour expliquer l'implication pénale des individus.

Mots-clés: Psycho-Pass; cyberpunk; technologies convergentes; life-course criminology.

$$
\begin{array}{r}
\text { Do you believe, what you hear } \\
\text { Can you believe, what you see } \\
\text { Do you believe, what you feel } \\
\text { Can you believe } \\
\text { What is real? } \\
\text { Futureal } \\
\text { Iron Maiden, in Virtual XI }
\end{array}
$$

\section{Introdução}

Futureal refere-se a algo que existe no presente, mas por se constituir como algo tão fora do comum aparenta ser irreal ou de um tempo futuro. É desta forma que se apresenta Psycho-Pass, um anime 1 japonês enquadrado no movimento (pós)cyberpunk centrado no tema do combate ao crime num futuro distópico no ano de 2112 . Com recurso a um conjunto de tecnologias convergentes

1 Anime é o termo japonês para animação, criado no primeiro quarto do século XX, caracterizado artisticamente por um grafismo colorido, desenhado à mão, personagens vibrantes e efeitos de câmara/ cinematografia como panning e zooming. Em 2015, cerca de $60 \%$ do total dos programas televisivos animados eram anime. 
atualmente existentes, a série apresenta inovações assentes em regimes de predictive analytics, tais como sensores cimáticos - nomeados de psycho-pass que medem, quantificam e aferem o estado mental, os níveis de stress (HUE) e os traços de personalidade dos indivíduos, calculando um coeficiente criminal que estes detêm para futuramente cometer um crime. Após alertar as autoridades para o criminoso latente, cabe aos agentes de autoridade aplicar a sentença atribuída pelo sistema tecnológico.

A pertinência desta aliança entre tecnologia e prática criminal consiste na implementação no Japão de regimes de predictive thinking, nomeado Yosokugata Hanzai Bogyo, um sistema de controlo policial com o objetivo de prever as áreas geográficas e as horas do dia em que é mais provável um determinado conjunto de crimes ocorrer. Para tal, este sistema aloca diferentes recursos técnicos e humanos de forma a evitar a prática criminosa (Japan Today, 2017) ${ }^{2}$. Por se projetar no futuro recorrendo a tecnologias atualmente em fase de desenvolvimento, a narrativa deste anime japonês levanta imensas pistas para reflexão, especialmente na interseção das tecnologias convergentes com o controlo social. Psycho-Pass, enquanto objeto artístico, permite-nos discutir sobre o uso de um conjunto de tecnologias convergentes no controlo social de toda uma organização social e, ao mesmo tempo, mostra-nos especialmente como aquelas reconfiguram esta nos mais diversos níveis. O nível criminal é o mais explorado no anime e é também o que pretendemos aprofundar neste artigo em termos de análise.

As tecnologias convergentes utilizadas resultam da atuação combinada de diferentes regimes de hardware e software, tais como nanotecnologia, biotecnologia, tecnologias de informação, ciências cognitivas, genética e robótica, que se traduzem em novos equipamentos e técnicas de controlo. Assim, em Psycho-Pass, a tecnologia, enquanto elemento de controlo social, acaba por estabelecer um enquadramento estrutural que, para além de pretender combater o crime, reconfigura igualmente as noções de crime e de criminoso. A tónica na compreensão do crime é de cariz desenvolvimental, colocando os eventos de vida no centro do entendimento da mudança dos coeficientes criminais dos indivíduos. No campo dos estudos sociais do crime, o envolvimento criminal é explicado, geralmente, apenas no que concerne ao seu aparecimento, não se debruçando sobre o que contribui para a estabilidade ou a mudança nos padrões das práticas criminais ao longo do tempo. A life course perspective e a life-course criminology, em particular, vêm colmatar esta lacuna, focando-se na compreensão do envolvimento criminal ao longo da trajetória de vida de

2 Também nos Estados Unidos estão em teste a composição de algoritmos (nomeado Public Safety Assessment) capazes de auxiliar os juízes a determinar o valor das coimas, o risco de fuga, a probabilidade de cometer novo crime antes do julgamento, e escapar a enviesamentos raciais. Outros algoritmos estão a ser criados de forma a prever a existência de crimes de colarinho branco, tornando obsoletas as técnicas policiais de profiling (Dewan, 2015). 
um indivíduo, isto é, sobre o início, a continuação e o término da prática do crime. Portanto, este processo é entendido como dinâmico, interativo e desenvolvimental, sujeito a flutuações ao longo de uma trajetória, sendo esta trajetória marcada por eventos de vida que podem levar um indivíduo ao crime, tal como nos aparece representado no anime. O controlo social, seja este formal ou informal, interfere, também, na compreensão deste fenómeno e aqui é construído e mantido a partir das tecnologias convergentes.

Assim, no âmbito deste artigo, pretendemos elaborar um exercício de reflexão que nos permita compreender a forma como se relacionam as tecnologias convergentes com as práticas criminais, através das narrativas produzidas nesta série em particular, ilustrando como as tecnologias podem informar e enformar a organização societal no geral e os sistemas de controlo criminal em particular. Para tal, cingimo-nos à primeira temporada de Psycho-Pass (22 episódios em que somos introduzidos a esta realidade) e recorremos analiticamente aos estudos visuais, devido à sua capacidade em explorar e compreender a vida social dos objetos (Carrabine, 2012) e por nos garantirem quadros analíticos adequados à plataforma que usamos para este exercício - o audiovisual.

A sociologia e criminologia visuais têm advogado não ser possível separar o crime e o controlo do mesmo da forma como estes são representados (Carrabine, 2012). Adicionalmente, os media visuais são usados não apenas como objetos visuais, mas também como instrumentos metodológicos que permitem produzir novo conhecimento sociológico (Burri, 2012: 47). Assumindo estas premissas, procedemos a uma análise etnográfica do conteúdo narrativo, integrando ambas as componentes áudio e visual (Li e Kuo, 2003), sendo que neste artigo apresentaremos a análise da primeira componente. Complementarmente, fazemos uma análise a partir das práticas sociais de troca (Appadurai, 1986; Rose, 2007), que consiste em perceber o formato artístico do anime, os contextos culturais em que o anime é produzido, como as tecnologias do presente são projetadas e implementadas no futuro, e como esta implementação das tecnologias no futuro é compreendida a partir dos quadros de referência do presente.

Este exercício de reflexão inicia-se com uma breve incursão sobre os produtos culturais e a aplicação das tecnologias convergentes num potencial novo paradigma futuro, seguido de uma contextualização teórica da life-course criminology. A partir deste enquadramento e tendo como base de análise os estudos visuais, descrevemos como são enquadradas as diferentes tecnologias na construção de elementos de dissuasão criminal, exploramos mecanismos de controlo social formal desenvolvidos e aplicados pelos seus agentes sociais, refletimos em torno das reconfigurações sociais do que é o crime e o criminoso e identificamos o tipo de fatores que são avançados para a explicação do envolvimento criminal dos indivíduos. 


\section{Produtos culturais e regimes tecnológicos convergentes: (pós) cyber- punk, anime, cyborgs e a transição do biohumano ao transhumano}

Os produtos culturais atuam regularmente como tradutores do potencial tecnológico junto dos públicos. O facto de não estarem presos à realidade permite-lhes projetar sobre cenários futuros e sobre a forma como as tecnologias se ajustam e contribuem para essa realidade. Esta tradução das diferentes possibilidades dos paradigmas tecnológicos convergentes revela-se na demonstração de ícones e de produtos que refletem diversos projetos políticos e tecnológicos disruptivos. H.G.Wells, em 1896, escreveu The Island of Doctor Moreau, onde enfatiza a fusão genética e corpórea entre humano e animal, criando novos seres híbridos através de homeostasia com recurso a vivissecção, levantando dilemas morais sobre a prática e o conflito entre o humano/racional com o animal/instinto. Heart of Darkness, escrito por Joseph Conrad em 1899, enfatiza a ideia de progresso e civilização, focando que o mal existe num espaço exterior ao que é civilizado, o selvagem, conclui que esse mesmo mal também existe dentro da civilização e do progresso, através de diferentes formas de dominação e controlo, em específico, o imperialismo e o racismo. Há, por isso, poucas diferenças entre as diferentes civilizações e entre os indivíduos.

No século XX, a tónica da relação entre tecnologia e prática criminal transitou para a aliança de regimes políticos a sistemas sociais de controlo distópicos. Brave New World, de 1932, escrito por Aldous Huxley, apresenta uma organização societal assente nos princípios do regime fordista de organização do trabalho, na qual os comportamentos desviantes são tratados através de medicação ou isolamento. 1984, de George Orwell, de 1949, apresenta um regime de controlo social centralizado, o Big Brother, no qual todas as ações dos indivíduos são monitorizadas através de regimes de CCTV e disciplinadas. No cinema, 2001: Space Odyssey apresentou aos públicos um sistema central senciente de controlo, personificado pela inteligência artificial HAL $9000^{3}$, algo similar a uma smarthome (domótica). Por se constituir como um sistema senciente, HAL 9000 é capaz de executar as suas funções, reajustar as suas diretivas e reagir a impulsos de autopreservação. Minority Report apresenta uma unidade policial de pré-crime, que atua tendo por base os pre-cogs, indivíduos ligados a uma rede computacional com a capacidade de prever ações criminosas antes de estas ocorrerem, colocando a tónica nos debates entre livre arbítrio e determinismo, tecnologia e humanismo. Mais recentemente, videojogos como Watch Dogs colocaram a smartcity de Chicago no centro da narrativa abordando a temática do controlo social e redefinindo o que é uma ação criminal e um criminoso, aliando um sistema central similar ao HAL 9000, 
com acesso tecnologia CCTV no qual tudo pode ser monitorizado e convertido em dados via smartphone.

É perante esta aliança simbólica entre tecnologias e produtos culturais que, durante a década de 1980, emerge no Japão o movimento cyberpunk aliado ao estilo anime ${ }^{4}$, de que são exemplos as obras Akira, de 1988, e Tetsuo, de 1989. Assente na premissa high tech, low life, o foco narrativo incide em civilizações assentes em tecnologias de ponta, mas com elevados níveis de pobreza e desigualdades sociais, para além do controlo social total por parte de organizações privadas ou do Estado. As personagens principais das obras cyberpunk são indivíduos marginalizados, vivendo numa distopia pós-industrial no qual a tecnologia escapa ao controlo humano. Por sua vez, o movimento pós-cyberpunk diferencia-se do cyberpunk pelo aspeto socioeconómico da realidade narrativa. Portanto, mantém a ideia de uma civilização com elevado potencial tecnológico, mas em que os indivíduos possuem um (relativo) bem-estar socioeconómico. A narrativa pós-cyberpunk incide em personagens que reforçam a ordem social, que se comportam dentro dos quadros normativos, não obstante a existência de uma ténue fronteira com a marginalidade e cujas escolhas conduziram à realidade distópica que vivenciam. Incluem com regularidade efeitos de remediation, a inclusão de outros tipos de media num determinado produto (Bolter \& Grusin, 2000). Foi também durante este período que a corrente do cyberpunk começou a ganhar notoriedade no Ocidente.

O cyberpunk prima pela reconfiguração do humano e a sua consequente fragmentação em bio, neo, meta e transhumano, incidindo na capacidade para transcender as limitações corpóreas biológicas (Bostrom, 2005; Butryn \& Masucci, 2009; Franklin, 2006), tendo por base o Cavaleiro Mecânico de Leonardo da Vinci, um ser (robótico) inteiramente funcional e autónomo que, embora limitado nas suas funcionalidades, promove a conceptualização de superar o biohumano durante a era Renascentista. A atual multidisciplinaridade das tecnologias convergentes pretende recuperar a 'unidade da natureza' renascentista, perdida após a especialização das disciplinas científicas que ocorreu na era do Iluminismo. Contudo, mais que simplesmente recuperar o espírito científico do Renascimento há uma ideia de ir para além do ideal Renascentista (Roco, 2007), fundindo não só as áreas do conhecimento, mas também as áreas tecnológicas.

A aliança de diferentes tecnologias deu azo a um conjunto de paradigmas convergentes tais como: i) Nanotecnologia, Biotecnologia, tecnologias de Informação, ciências Cognitivas (NBIC), ii) Bits, Átomos, Neurónios, Genética (BANG), e iii) Genética, Nanotecnologia e Robótica (GNR) que fomentam

4 Resultando na implementação de uma estratégia de exportação cultural, Cool Japan teve no anime e nos sistemas de media-mix (Ito, 2006) o seu principal foco. Embora não exclusivo à estratégia do Cool Japan (Alison, 2009; Condry, 2009), o anime e o cyberpunk enfatizaram a relação entre o avanço tecnológico e a prática criminal (Muri, 2003). 
novas promessas, esperanças, expectativas e riscos. Assim, os novos paradigmas assentes nas tecnologias convergentes prometem transformar as arquiteturas individuais, o biohumano, e sociais, a estrutura. Esta relação entre a tecnologia e a cibernética possibilita o desenvolvimento de sistemas auto-governáveis através da medição de sinais e pela interação com as células humanas e sistema nervoso. A finalidade destas tecnologias não passa unicamente por comunicar com a ação humana, mas também (e sobretudo) para comunicarem entre elas. O trabalho na esfera do material (hardware) e do imaterial (software) reflete-se em inovações como Realidade Aumentada (RA) e Realidade Virtual (RV) que transforma a informação física em redor aos humanos em dados quantificáveis e mensuráveis. Estas inovações presentes no género cyberpunk constituem a base para a criação de datacentros ubíquos de informação computadorizada, ou seja, toda a ação humana é transformada em dados passíveis de serem analisados. A este fenómeno juntam-se novas e invasivas formas de modificação do corpo humano. Ao aliar a robótica, à nanotecnologia, à genética, à biologia e às TIC todos os dados e informações sobre o corpo humano são imediatamente recolhidos, analisados e de passível sanção.

A crescente incorporação de tecnologias no corpo humano, iniciada aquando da implementação das primeiras próteses na década de 1920, fez emergir a figura do cyborg e transhumanos. Cyborg, um termo inicialmente cunhado por Clynes e Klyne em Cyborgs \& Space na década de 1960 (Duarte, 2014; Ihde, 2008; Park, 2014) cresceu a partir dos trabalhos de Haraway (Gane \& Haraway, 2006; Haraway, 1985) como forma para transcender as manifestações de sexo (biológico) e género (como construção social), contestando o tradicional binómio homem/mulher e estimulando divisões categóricas entre facto e ficção (Shields, 2006). Também Latour (Latour, 2008; Rae, 2014) refletiu sobre o híbrido e como a sua existência gera enorme imprevisibilidade em vastas redes compostas por pessoas e objetos. A emergência e coexistência atualmente de body hackers (Park, 2014), grinders (Duarte \& Park, 2014) e self-made cyborgs (Coenen, 2014; Dubiel, 2011) suscitados como elementos cyberpunk cria novas possibilidades de interrelação social que escapam à determinação biológica, formando-se como distintas formas de modificação corporal (Duarte, 2014; Olivares, 2014). Por isso, a identidade serve como uma autodefinição em contraste com heterodefinições na qual se demarcam zonas de fronteira e exclusão (Ribeiro, 2011): novas normas sociais e novas desigualdades. A corrente cyberpunk apresenta a relação entre biohumanos e neo/meta/transhumanos, gerando novas formas de conflito e de estigma, mas acima de tudo, de superação da condição humana. O cyborg resulta num triplo hibridismo: biológico e máquina; realidade e ficção; físico e virtual. No dualismo bio/máquina, o estigma da figura do cyborg ocorre no universo da ficção (e.g. sem compreender a essência do sentir), seres que não compreendem a subjetividade humana. $\mathrm{Na}$ dicotomia entre realidade/ficção, o estigma da 
ficção científica (Bowman et al., 2007a; Bowman \& Hodge, 2007) remonta ao que é exequível e o imaginado. Em relação ao binómio físico/virtual, o termo de digital now promovido pela escritora Abha Dawesar (2013) reflete sobre a quebra do tradicional fluxo entre passado-presente-futuro: as redes virtuais estão regularmente presentes, possibilitando a um corpo presencial simultaneamente agir num espaço físico (e.g., sentado na mesa do café) e interagir num mundo virtual (e.g. postando texto e imagem nas redes sociais online). $\mathrm{O}$ virtual funde-se com o físico conduzindo à morte do self e à supremacia do $I$.

Tecnologias convergentes promovem resultados divergentes. Portanto, a fusão de diferentes tecnologias dá azo a múltiplas formas de evolução. Se a figura do cyborg incidiu na manipulação genética do humano, contrastando com implantes ou elementos robóticos ou com o contributo das tecnologias de informação na alteração das capacidades de processamento e cognitivas do humano, o transhumanismo permite imaginar uma evolução não mais dependente da biologia e sobretudo não-externas ao ser humano e com enfoque nas diferenças entre o cérebro biológico/químico e o cérebro computacional (Jones, 2007). Centrar a ação do cérebro somente pela sua capacidade cognitiva é ignorar a tomada de decisão humana através da consciência.

As tecnologias e as TIC, em particular com as suas características de validade, replicabilidade e programação permitem o controlo da ação humana, de uma forma similar a como o relógio permitiu o controlo do tempo: A tecnologia "conhece" e define os parâmetros do que é normal, saudável e familiar, como é que é pré-programado, previsível e antecipado, enquanto o desvio é lido como emergência (Rapoport, 2013: 213).

Mas são estas formas de validação e replicação tecnológicas estanques e reificadas? Psycho-Pass recorre aos quadros de referência tecnocientíficos para questionar se pode um indivíduo ser catalogado e punido com base numa ação que se desvia da norma no espaço e no tempo. Torna-se, portanto, necessário analisar as diferentes trajetórias (sociais) de um indivíduo para compreender o seu comportamento criminal.

\section{A life-course course criminology: uma perspetiva desenvolvimental na compreensão do crime}

Ao contrário das teorias criminológicas e sociológicas explicativas do crime que são, geralmente, mais estruturais e estanques, a criminologia desenvolvimental oferece uma descrição e compreensão das mudanças do comportamento delinquente do indivíduo ao longo da sua trajetória de vida (LeBlanc, 2006: 195) e discute a progressão ou a escalada do comportamento criminal (Piquero and Mazerolle, 2001). O enfoque está, portanto, nos eventos que ocorrem ao longo da trajetória de vida de um determinado indivíduo que pode influenciar o seu 
envolvimento criminal, que não está, portanto, pré-determinado e que pode sofrer alterações nas diferentes fases de vida, levando-o a persistir ou a desistir da prática do crime.

De acordo com Sampson e Laub (1993), dois conceitos são centrais na análise das dinâmicas do curso da vida. O primeiro é o conceito de trajetória, ou o caminho que se desenvolve ao longo do curso da vida marcado por uma sequência de transições. As trajetórias têm pelo menos três dimensões: entrada, sucesso e tempo (Thornberry, 1997). A dimensão da entrada reconhece que nem toda a gente entra em determinadas trajetórias desenvolvimentais (e.g. algumas pessoas cometem crimes, outras não). A dimensão do sucesso reconhece a variação no conteúdo e contexto das trajetórias desenvolvimentais entre as pessoas (e.g. algumas pessoas alcançam o sucesso no crime, enquanto outras não). O tempo em que ocorrem determinados eventos ao longo da trajetória pode ser significativo na alteração da trajetória desenvolvimental enquanto ofensor (e.g. ser pai em idade adulta pode alterar a trajetória criminal numa maneira positiva, mas este mesmo evento ocorrendo durante a adolescência pode ter efeitos deletérios, conduzindo a um maior envolvimento numa trajetória criminal) (Thornberry, 1997; Piquero \& Mazerolle, 2001: ix). O segundo conceito é o de transição ${ }^{5}$ ou de eventos de vida (e.g. o primeiro ato criminoso) encaixados numa trajetória. As transições ao longo da vida de um indivíduo tendem a ser consequentes em termos da posição do indivíduo no curso da vida, e as transições que ocorrem ao longo de todo o ciclo de vida pode tanto fortalecer padrões de comportamento emergente ou alterar, redirecionar ou transformar as trajetórias desenvolvimentais (Rutter \& Rutter, 1993). As análises realizadas às dinâmicas do curso de vida, portanto, focam-se nos contextos de transição. Noutras palavras, as análises do curso de vida "focam-se na duração, tempo e sequência dos principais eventos de vida e nas suas consequências para o desenvolvimento posterior da trajetória” (Sampson \& Laub, 1993: 8; Sampson \& Laub, 2001: 23).

Fortemente relacionado com o estudo das trajetórias e transições está o conceito de ponto de viragem (turning-point) ou uma mudança significativa na direção do curso desenvolvimental de alguém (Elder, 1985). Os pontos de viragem podem levar a uma alteração abrupta ou gradual do curso desenvolvimental de alguém. Elder e os seus colegas (1991) afirmaram que para algumas pessoas os pontos de viragem podem produzir mudanças radicais na história de vida que separam o passado do futuro. Sampson e Laub (1997) defendem, no entanto, que para a maioria das pessoas os pontos de viragem é mais gradual, não se dando de uma forma tão repentina.

É ainda importante referir, dentro desta perspectiva, que existem mecanismos fundamentais através dos quais o ambiente social se altera e as trajetórias 
influenciam a causa e a substância das vidas humanas (Elder, 2001: 5-7). Dois desses mecanismos ${ }^{6}$ são o tempo social (social timing) e as vidas interdependentes (linked lives). Primeiro, e de acordo com o princípio do estádio da vida, o impacto pessoal de qualquer mudança depende de onde os indivíduos estão nas suas vidas aquando da mudança. Depois, depende igualmente das relações sociais que os indivíduos experienciam em todo o ciclo de vida. O princípio das vidas interdependentes refere-se à interação entre o indivíduo e o seu mundo social em todo o ciclo de vida - família, amigos e colegas de trabalho. Em grande medida, as transformações macro-históricas são experienciadas pelos indivíduos através destes mundos micro-institucionais.

Portanto, constatamos que para Elder o curso da vida é definido como caminhos que são realizados através das idades diferenciadas que se vão tendo ao longo do ciclo de vida, no qual a diferenciação de idades é manifestada nas expectativas e opções que incidem sobre os processos de decisão e o curso de eventos que dão forma às fases de vida, transitórias ou de viragem (Elder, 1985: 17). As transições etárias estão imbuídas em instituições sociais e estão sujeitas a mudanças históricas (Elder, 1985).

Parte da relevância desta abordagem assenta na perspetiva dinâmica de compreender como o comportamento criminal se desenvolve ao longo do tempo e como este é influenciado sistematicamente pelos eventos nas diferentes faixas etárias que ocorrem ao longo do curso de vida (Piquero \&Mazerolle, 2001), sejam estes eventos mais micro ou macro estruturais.

Considerando a descrição da perspectiva do curso de vida, os seus principais conceitos e a forma como estão inter-relacionados, Sampson e Laub (2001: 31) põem em causa a possível identificação dos falsos positivos e dos falsos negativos ${ }^{7}$. Os autores afirmam que conclusões em torno da inevitabilidade de comportamentos contínuos anti-sociais são questionáveis e abre-se um maior espaço para a emergência de descontinuidades nestes comportamentos.

Posto isto, podemos perguntar-nos: e se tivéssemos uma tecnologia disponível que nos permitisse fazer esta previsão com maior acuidade do comportamento criminal, evitando os falsos positivos e os falsos negativos? Ou se tivéssemos uma tecnologia que nos mostrasse em que fase o indivíduo está ao nível do envolvimento criminal? Ou até se tivéssemos uma tecnologia que nos permitisse reduzir os constrangimentos externos e permitisse a felicidade de todos os indivíduos? Como seria esta sociedade com esta tecnologia disponível e como reconfiguraria as relações sociais entre os indivíduos no domínio criminal?

6 Os outros dois mecanismos, que não são neste artigo desenvolvidos, são o tempo histórico (lives and historical times) e a ação humana (buman agency).

7 Os falsos positivos e os falsos negativos correspondem a uma falha na previsão do comportamento delinquente ou criminal. O primeiro aplica-se a um indivíduo que é previsto ser perigoso no futuro, mas que acaba por não o ser; o segundo a um indivíduo que é previsto não ser perigoso no futuro e acaba por o ser (Lab, 2004). 
Após este enquadramento da perspectiva do curso de vida e este questionamento, pretendemos compreender como quando esta perspetiva aliada às tecnologias convergentes pode gerar uma nova concepção societal. Esta organização societal distinta em análise é a apresentada em Psycho-Pass. Exploramos, portanto, como as tecnologias são usadas no sentido de servir uma determinada concepção social de crime e criminoso, desenvolvendo mecanismos de controlo social específicos.

\section{As tecnologias convergentes e o fenómeno criminal: análise no anime Psycho-pass}

O tecnofuturo apresentado em Psycho-Pass coloca os indivíduos ligados a um sistema central de controlo digital. O psycho-pass, como um sistema omnipresente de avaliação mental, codifica o bem-estar dos indivíduos, categorizando-o como coeficiente criminal de forma similar a Minority Report e à presença totalitária do Big Brother em 1984. Contudo, Psycho-Pass atravessa a ténue linha que distinue o movimento cyberpunk do pós-cyberpunk. A realidade apresentada é distópica por possuir um sistema universal de controlo no qual a ação humana é determinada pelo computador central Sibyl. É este dispositivo que define o nível educacional e a profissão dos indivíduos, mas acima de tudo se demonstram potencial para serem criminosos ou não. A sua vertente pós-cyberpunk reside no facto de diluir este efeito omnipresente e totalitário. Os indivíduos vivem num regime democrático, com eleições livres e têm acesso a um vasto conjunto de bens materiais.

Psycho-Pass apresenta uma hierarquia de funções na deteção do comportamento criminal: i) sistema Sibyl, ii) drones e CCTV, iii) agentes policiais, iv) enforcers e v) dominators. A transição de uma aparente hierarquia linear é substituída por um sistema circular, no qual todas funções respondem perante o sistema Sibyl ${ }^{8}$.

O sistema Sibyl é composto por um regime de colmeia (bive mind) constituído por 247 indivíduos não-contaminados, similar a um grupo de controlo, que determina a definição de normalidade. Ao contrário de outros produtos culturais ${ }^{9}$ que apresentam um sistema central que ao ser desligado é destruído, Psycho-Pass apresenta uma formação de hubs, ou seja, um sistema periférico. Sempre que uma célula é destruída, outro indivíduo é acrescentado. Este sistema de processamento é também destituído de um sistema inteiramente central: as armas (dominators) usadas pelos agentes de segurança e pelos enforcers comunicam diretamente com o sistema Sibyl, mas os restantes equipamentos 
não. Esta priorização diminui a margem de erro e previne a sobre-requisição de dados do sistema.

Os Drones e CCTV atuam como os primeiros agentes de vigilância, constantemente monitorizando os indivíduos e os espaços que frequentam. A sua função é de atuar, conter e alertar os agentes policiais perante qualquer distúrbio à ordem. A sua vantagem operacional é serem capazes de projetar e identificar a aptidão para a realização de um crime, mesmo antes do indivíduo que o vai cometer saber. Para tal, os drones e CCTV veiculam uma ligação entre robótica, TIC e ciências cognitivas.

Os agentes policiais são os elementos intermédios. Respondem perante o sistema Sibyl, atuam em consonância com os drones e CCTV, procedem à investigação criminal e utilizam recursos como os enforcers e os dominators e são compostos por biohumanos e transhumanos.

Os enforcers, também eles biohumanos ou transhumanos, são tratados como cães de caça, os farejadores, cuja principal função consiste em perseguir criminosos manifestos e latentes. Atendendo que são indivíduos já referenciados pelo sistema, a sua outra função é evitar que os agentes policiais sejam contagiados pela ação criminal.

Os dominators são dispositivos eletrónicos com a função de medir no imediato os níveis de stress (HUE), atribuindo o nível de violência correto para a resolução de cada um dos casos problemáticos. Ou seja, determina se os agentes e os enforcers podem recorrer a força letal, ou a outras alternativas como paralisar o criminoso. Quando ativados, os dominators registam toda a informação: se, por um lado, termina com a violência policial, por outro, reforça o caráter ubíquo da tecnologia.

Um agente que não cumpra uma ordem de disparo letal é punido ou no mínimo tem de justificar a sua ação (episódios 1 e 2). O efeito latente é conferir legitimidade a esse nível de agressividade letal e tornar os agentes de segurança em meros utilizadores de equipamentos. Os dominators apresentam uma forte ligação às tecnologias de base genética. Por estarem bloqueados ao ADN do utilizador, um criminoso não se pode apropriar da arma. Este efeito de controlo na distribuição de armas limita o acesso que os cidadãos e os criminosos têm. Os dominators estendem a base convergente da tecnologia: se através da biotecnologia registam o ADN do seu utilizador, é através das TIC que comunicam diretamente com este e criam uma interface gráfica que determina o seu âmbito de ação. Contudo, os dominators não comunicam unicamente com os agentes e com os enforcers, mas sobretudo com o sistema Sibyl. Ao medirem os níveis de stress dos criminosos recorrem às ciências cognitivas e a execução da ordem de eliminação dá-se através da nanotecnologia pela desintegração molecular dos indivíduos. 


\subsection{Tecnologias convergentes na construção de mecanismos de controlo social e de dissuasão criminal: biohumanos, cyborgs e transhumanos}

Alguns elementos tradicionais do movimento cyberpunk, como a incorporação tecnológica, relacionam-se diretamente com a aplicação de diferentes paradigmas tecnológicos convergentes e serve para demonstrar como a organização societal se estrutura. É através desta ação que o movimento cyberpunk envolve tecnologias existentes no presente, projeta-as num futuro e demonstra o seu potencial distópico. Esta ação futureal contribui para a discussão da aplicação tecnológica. As tecnologias são por isso reais e aplicáveis.

Um dos principais traços diferenciadores de Psycho-Pass dentro do registo cyberpunk assenta na criação da HUE e na sua capacidade de diferentes elementos tecnológicos observarem, registarem e diagnosticarem a propensão mental para um indivíduo cometer um crime. Esta ligação entre ciências cognitivas e TIC apresenta um elemento de previsão, que cataloga e determina a sua ação futura.

Uma das inovações apresentadas em Psycho-Pass refere-se ao processo de plastinação, ou seja, a incorporação da nanotecnologia através da criação de um polímero de revestimento capaz de preservar a degeneração de pele e do corpo humano. A fusão entre o bio e a máquina, quer pela incorporação de tecnologias nos corpos ou pela integração sistemática de equipamentos, reforça a ideia de cyborg/híbrido. Todavia, o anime reflete sobre o que constitui um humano e qual é o ponto de transição em que se transforma em cyborg:

Toyohisa Senguji (TS) - É uma questão de grau. Por exemplo, você, você também tem bastante de cyborg.

Jornalista $(\mathrm{J})$ - Mas eu não uso braços artificiais, pernas artificiais, ou órgãos artificiais.

TS - Mas tem algum tipo de terminal portátil de informação, certo?

$\mathrm{J}$ - Bem, $\operatorname{sim} . .$. mas não tem toda a gente?

TS - E um dispositivo de roupa?

J - Com certeza.

TS - E em casa, provavelmente tem um sistema de automação doméstica e uma secretária de inteligência artificial. E o que lhe aconteceria se todos os dados existentes nesses dispositivos se perdessem devido a um desastre ou acidente?

J - Bem... não conseguiria fazer nenhum trabalho até que fossem restaurados

TS - Quando se confia tanto da nossa vida quotidiana a esses dispositivos eletrónicos, o argumento que não é um cyborg não é muito convincente (...) Esses terminais portáteis são já o seu segundo cérebro. [ep. 9, 6:50] 
Constatamos, assim, uma diferença na transformação humana, seja pela incorporação de elementos tecnológicos no corpo humano, seja pela dependência que o humano passa a ter da tecnologia para a realização de tarefas diárias. Regista-se deste modo uma dupla capacidade do sistema Sibyl: a de registar informação cognitiva de biohumanos e a de criar cyborgs e transhumanos, ou seja, de definir o potencial criminal em cérebros biológicos e computacionais e de aplicar sanções a corpos biológicos e robóticos.

O foco na ténue linha entre o físico e o virtual e como as tecnologias de criação holográfica são capazes de materializar objetos, são expostos no episódio 4. A detetive Akane reflete sobre a (aparente) neutralidade da tecnologia e como algo que está para além das noções de bem e de mal:

Detetive - Usar a internet não é como usar facas para cozinhar ou usar papel para escrever? Não tem nada a ver com o bem ou o mal. É tipo... está lá, por isso aceitamos e usamos. [ep. 5, 4:44]

Esta lógica é continuada no episódio 9 quando a conversão de humano em cyborg é equiparada à transformação do humano em deus. Ao possibilitar transformar o corpo biológico em robótico é possível estender a longevidade do humano. Contudo, quando questionados sobre o possível interesse que um criminoso latente teria em prolongar a sua vida, Kogami, um enforcer, responde: "A vida como criminoso latente não é o tipo de coisa que queres que se arraste para sempre" [ep. 9, 6:12]. Na sequência, Akane menciona: se um dia o sistema social se desenvolver, os direitos dos criminosos latentes podem melhorar [ep. 9, 6:22]. Esta condição hipotética assenta numa perceção especulativa, no qual, no futuro, pode ser que os direitos dos criminosos latentes melhorem, mas que subordina a ação social ao desenvolvimento tecnológico.

Em Psycho-Pass a incorporação cyborg apresenta máquinas que se assemelham em funções ao humano e humanos que, pelo recurso a próteses robóticas ou pela modificação genética, ultrapassam a condição biohumana. Ainda assim, a sua informação biométrica é retirada e convertida em informação passível de ser analisada pelo sistema Sibyl. O controlo dos corpos é feito pela manipulação dos genes, enquadrado em sistemas de vigilância omnipresentes, que colhem substâncias e registam impressões digitais/genéticas. Os corpos interagem e reagem com os organismos de poder, mas a inovação da implementação da nanoescala incide na sua perda de capacidade de resistência. A informação é retirada sem que o seu detentor se aperceba disso. Este efeito distópico contrasta com a forma como os indivíduos manipulam o espaço exterior, em particular através da realidade aumentada e realidade virtual. Os espaços habitacionais, pela ligação TIC com a nanotecnologia, permitem a criação de hologramas fabricáveis. Os indivíduos podem facilmente escolher que indumentária usar, ou como decorar a habitação, criando e replicando o produto imediatamente. 
Psycho-Pass não ignora o passado histórico. Pelo contrário, abarca-o. Referências culturais como 1984 e Brave New World são incluídas como efeito de remediation. Ambas as obras são visíveis, verbalmente referidas e estão na posse de diversas personagens, reforçando a forma como a vida social é vigiada e controlada. A ideia que os indivíduos conhecem estas obras e sabem os problemas que suscitam serve para enfatizar o domínio do sistema Sibyl e que esta ideia de sociedade foi construída como sequência temporal, e não como uma realidade paralela.

O objectivo central de manter os níveis de stress social/individual e manter os indivíduos calmos e passivos (Brave New World) é realizado através de um controlo social total em que tudo é visto, analisado e mensurado. Para além disso, este controlo social total é manifestado por ser no interaior do indivíduo. Esta concepção de que foram os indivíduos que desejaram esta forma de domínio é consistente com a vertente cyberpunk e com a aliança entre as formas de controlo coletivo e os desejos individuais através do controlo omnipresente de uma dada esfera informacional aliada à aumentação cibernética dos corpos. O controlo não surge somente como externo, mas também interno ao seu corpo, como um mecanismo que se assume como uma forma de poder, de controlo dos corpos, das ações, atitudes, discursos, mas acima de tudo das suas representações. É uma forma de interpelação (Althusser, 2014). O anime debate também as formas de controlo do aparelho ideológico do estado (Althusser, 2014), designadamente a correlação entre governo e cidadãos, mediado através do aparelho jurídico, na voz da detetive Akane Tsunemori:

Detetive - A lei não protege as pessoas. As pessoas protegem a lei. As pessoas sempre detestaram o mal e procuraram uma forma benigna de viver. Os seus sentimentos - a acumulação dos sentimentos dessas pessoas - são a lei. [ep. 22, 6:24]

\subsection{Os mecanismos de controlo criminal formal desenvolvidos e aplicados pelos seus agentes sociais}

Psycho-Pass acompanha o desenvolvimento narrativo de três personagens: Akane Tsunemori, uma agente policial/detetive, Shinya Kogami, um enforcer/criminoso latente, ambos ao serviço do Public Safety Bureau Criminal Investigation Division, e Shougo Makishima, o criminoso não detetado por Sibyl. Cada personagem desempenha o seu papel nesta organização societal e é através delas que é possível compreender a aplicação dos mecanismos de controlo e dissuasão criminal formal analisados acima.

Uma das principais forças do sistema Sibyléa sua ominipresença tecnológica, que regula e disciplina os comportamentos. Osenforcers e os detetives são propriedade do sistema e as suas funções estão devidamente definidas e interiorizadas. 
Ela [a detetive] vai ser a vossa [farejadores] segunda dona. [ep. 1, 6:26]

Nós caçamos a presa e tu observas. É basicamente isso. [ep. 1, 08:51]

A sua capacidade em detetar tendências criminosas em tempo real e em transmitir essa informação para os restantes equipamentos, como drones e CCTV, leva ao controlo social total. Ainda assim, o sistema suporta-se igualmente em regimes de profilling encetados pelos enforcers, como um modelo de previsão alternativo ao implementado pelo sistema Sibyl.

Detetive - No final, foi o senhor Kogami [farejador] que identificou o culpado. Só de pensar que ele descobriu como o culpado pensava e antecipou as ações...

Outro detetive - é assim que os enforcers atuam. Eles podem fazer precisamente isso porque têm as mesmas tendências psicológicos que os criminosos. [ep. 3, 19:58-22:42]

A proximidade manifesta entre criminosos e enforcers faz com que os mesmos interiorizem a sua própria tendência criminosa, mesmo quando se limitam a aplicar técnicas de investigação policiais ao serviço do sistema e devidamente legitimados por ele.

\section{Detetive - Como consegues saber quem é criminoso mesmo sem usares um scanner? \\ Cão de caça - Um animal consegue farejar o cheiro de outro animal.} [ep. 2, 13:04-13:07]

A arma utilizada por excelência por parte dos agentes policiais e enforcers é o dominator, que só pode ser utilizada por estes indivíduos e é controlada superiormente pelo sistema Sibyl. A arma determina, quando apontada a um indivíduo, se o mesmo deve ser alvo de disparo ou não e, em caso afirmativo, que tipo de disparo deve ser efetuado. Portanto, os agentes têm apenas de executar a ordem do sistema que é operacionalizada através do dispositivo tecnológico:

Podes fazer somente o que o dominator te diz. Se diz disparar, então simplesmente dispara. (...) Se está programado para o modo básico, ele usa o paralyzer, e irá somente paralisar o alvo, enquanto nós levamo-lo para custódia e será um caso arrumado (...) [a detetive segura a arma pela primeira vez e ouve]: Diagnóstico Psicológico Portátil do dominator e do Sistema de Supressão Ativado (...). Você é um utilizador válido. [ep. 1, 7:46-8:19] 
O tipo de disparo varia entre meramente paralisar o indivíduo (modo paralyzer) até eliminar/matar o indivíduo: Depois do modo paralisar, existe a eliminação letal: "Modo enforcer é Eliminação Letal". [ep. 1, 14:43]

O controlo tecnológico do sistema Sibyl apodera-se de todas as esferas da vida social. A sua capacidade em ler os talentos dos indivíduos e maximizar o seu potencial e níveis de felicidade eliminou as escolhas que estes poderiam realizar, tal como a seleção da sua profissão. $\mathrm{O}$ anime apresenta uma comparação entre os modos de vida antes e após a implementação de Sibyl.

Cão de caça - A detetive pode ser quem quiser. Pode escolher qualquer tipo de vida. Até ficou agoniada por causa disso, certo? É incrível. Tu és como aquelas pessoas daqueles tempos anteriores ao Sistema Sibyl ser criado. Atualmente, o Sistema Sibyl lê os seus talentos e diz-lhe que tipo de vida é que lhe trará maior felicidade. E ainda assim discute o seu propósito na vida? A razão pela qual nasceste? Eu nem sequer imaginava que existiam pessoas que stressavam sobre coisas como essas! Eu fui marcado num teste do psycho-pass quando tinha 5 anos. Tornei-me um criminoso latente desde então. Sem possibilidade de reabilitação através de tratamento. É por causa disso que estou aqui, agora. E prefiro ser um cão de caça do Gabinete e ter de realizar contratos de assassinatos do que passar o resto da minha vida num estabelecimento de quarentena. Essa foi a única escolha que alguma vez tive. [ep. 2, 17:32-18:03]

Este controlo é especialmente visível nos próprios enforcers, já que enquanto criminosos latentes ao serviço das agências policiais, têm os seus movimentos controlados, sem qualquer espaço para se movimentarem livremente fora da sua área de atuação profissional.

Cão de caça - Nós, os Enforcers, somos prisioneiros, sabe? Mesmo quando não estamos de serviço não há nenhum sítio que possamos ir para além do piso do CID e dos nossos aposentos. [ep. 2, 15:22-15:30]

\subsection{Reconfigurações sociais do crime e do criminoso}

Numa organização societal em que as tecnologias convergentes desempenham um papel tão central e implacável no controlo social, nos seus mais diversos níveis, incluindo o nível criminal, o crime e o criminoso sofrem reconfigurações necessárias. Não apenas a tecnologia delimita a identificação do que é o crime e quem é o criminoso, como executa em função dessa mesma identificação, funcionando como juiz e carrasco. 
O crime será aquele que o sistema Sibyl definir enquanto tal, sendo que todo o manancial tecnológico, já identificado anteriormente, dissuade a prática criminal, assim como identifica e executa uma determinada ação (paralyzer ou lethal eliminator) face a um indivíduo criminoso.

Tratando-se de um sistema total, no sentido em que determina e está presente nas trajetórias de vida dos indivíduos, consegue identificar o surgimento dos coeficientes criminais de forma continuada e em tempo real. Portanto, a atuação sobre o indivíduo com um coeficiente criminal pode ser realizada antes mesmo do ato criminal ocorrer. O criminoso é, assim, aquele indivíduo que o dominator identifica, através do seu psycho-pass, como tendo um coeficiente criminal, estado que o levará futuramente a cometer um crime. O anime demonstra que a utilização da arma dominator é essencial para a construção da definição de assassino: se um indivíduo usar qualquer outra arma para matar alguém é identificado como criminoso. Somente as ações permitidas pelo dominator são consideradas como violência legitimada.

Esta binarização de estados inocente-culpado está fortemente integrado da lógica binária das TIC-0-1, no qual apenas são possíveis dois estados; o mesmo acontece no registo dual entre verdade-mentira, como, por exemplo, nos detetores de mentiras. Esta simplificação sustenta a ilusão de um sistema inteiramente racional e lógico, no qual a tecnologia elimina a intervenção subjetiva do humano e não comete erros. Se a mesma ação for realizada recorrendo a um dominator, a ação torna-se legitimada.

No primeiro episódio da série são-nos apresentados dois tipos de criminosos. O primeiro criminoso a ser apresentado relata a sua própria experiência, e assume como ao longo de toda a sua vida tentou não ser identificado pelo sistema como um desviante, fazendo tudo aquilo que é suposto um indivíduo fazer. A partir do momento em que é identificado pelo sistema como criminoso, e considerando que a atuação sobre ele será de tal forma aniquiladora que não terá mais uma oportunidade de seguir um trajeto normativo, o indivíduo liberta-se de todas as restrições que lhe tinham sido impostas até então e age, criminalmente, satisfazendo as suas vontades.

Toda a minha vida caminhei sobre cascas de ovos, a tentar fazer o meu melhor para não chatear ninguém ou ser um incómodo para alguém. Apesar de tudo, um detetor descobre um problema em mim apenas uma vez e pronto! Tratam-me como um criminoso. É o fim para mim. Agora que fui detetado, acabou tudo. Emprego, casamento, é impossível agora. Tudo bem. Mantive-me reprimido toda a minha vida. Agora posso fazer tudo o que quero. Levarei tudo o que quero. Matarei todos aqueles de quem não gostar. Sempre quis ter sexo com uma mulher 
bonita como tu, nem que fosse uma única vez... com uma mulher real e não uma virtual [e começa a violar a mulher]. [ep. 1, 9:50-10:42]

Portanto, verificamos que no caso deste indivíduo, assim como aparece noutros exemplos ao longo da série, houve um evento que funcionou como um ponto de viragem na sua trajetória (Elder, 1985), levando ao comportamento criminal. $\mathrm{O}$ evento foi a identificação pelo próprio sistema de que o seu psycho-pass estava a sofrer alterações, criando um coeficiente criminal e sendo necessária a intervenção imediata. É possível observar igualmente que no momento em que Sibyl ativa o coeficiente criminal, os indivíduos são marcados como potenciais criminosos e privilégios sociais como o emprego e o casamento são lhe negados. Do momento a que é marcado até efetuar o crime, é criada estruturalmente uma self-fulfiling prophecy: ao desprover os indivíduos de todas as organizações sociais e fontes de socialização, o sistema força-o a recorrer ao crime, criando uma ilusão de previsão e predictive thinking, descobre o resultado porque cria as condições para o fundamentar.

O segundo tipo de criminoso que é apresentado é o criminoso latente, que no âmbito dos estudos da life-course criminology corresponderia a um career criminal ou permanent offender (see Kyvsgaard, 2003 and Savage, 2009). Estes são os indivíduos em que o coeficiente criminal ultrapassa um determinado valor especificado (300 pontos acima) e se entende que são incuráveis, podendo agir de forma criminosa durante toda a sua trajetória de vida. Não sendo reabilitáveis, o seu estatuto decresce e deixam de ser considerados sequer humanos. É o caso dos enforcers, ou bunting dogs como são apelidados pelo sistema, que por pensarem como um criminoso latente entende-se que tenham a capacidade de identificar outros criminosos e servir como mais um instrumento ao serviço do sistema.

Não penses que as pessoas que vais conhecer são humanos como nós. O coeficiente criminal dos seus psycho-pass excederam um valor específico. São pessoas de caráter corrompido. Normalmente, não seriam completamente isolados enquanto criminosos latentes. Todavia, permitem-lhe que venham para o mundo exterior com o único propósito de atrair criminosos como eles. São cães de caça. São animais usados para caçar animais. São aquilo a que chamamos Enforcers. Serão os seus [do detetive] subordinados. [ep. 1, 5:35-6:02]

No caso de indivíduos que o sistema Sibyl entenda que são ainda curáveis, a arma dominator determina que deve ser usado um sistema paralyzer, permitindo depois trabalhar o indivíduo de forma a que ele volte a ter um psycho-pass neutro. Por outro lado, no caso dos criminosos latentes o sistema entende que não há a possibilidade de reabilitação e, por isso, devem ser aniquilados. 
Cão de caça - Um oráculo do Sistema Sibyl. Diz que o Nobuo Okura não é alguém que seja mais necessário a este mundo. Nada, incluindo terapia, funcionará com ele. O julgamento é que já não há reabilitação possível. [ep. 1, 14:59-15:22]

A única forma de não serem aniquilados é o de se sujeitarem a trabalhar para o sistema Sibyl, como instrumentos do próprio sistema, na "caça" de outros indivíduos com o mesmo tipo de coeficiente criminal.

Registamos, assim, que o enfoque está, portanto, nos eventos que ocorrem ao longo da trajetória de vida de um determinado indivíduo que pode influenciar o seu envolvimento criminal, não estando este pré-determinado. A persistência ou desistência do comportamento criminal é encarada de diferentes formas, dependendo do tipo de criminoso que é identificado pelo sistema. A desistência criminal será algo possível num criminoso até um determinado patamar (até 100). O criminoso latente é visto como alguém que persistirá na prática criminal ao longo de toda a sua trajetória, daí a resposta do sistema ser também mais radical.

Não obstante a capacidade que o sistema tem em definir o coeficiente criminal a qualquer momento, o predictive system é posto em causa nesta série por uma das detetives, que representa, de certo modo, o elemento humanizador de todo o sistema tecnológico. Logo no primeiro episódio, uma das vítimas de um crime, devido à situação extrema de stress a que é exposta, acaba por ser contaminada com um coeficiente criminal (o psycho hazard, que será abordado no próximo ponto). Ora, nessa situação, o hunting dog tenta matá-la, uma vez que o dominator dá a indicação do modo Lethal Eliminator. A detetive, não aceitando a situação, não permite que ela seja morta, contrariando as ordens do sistema Sibyl. Mais tarde, quando a vítima-criminosa latente começa a receber tratamento, o seu psycho-pass começa a recuperar e deixa de ser alvo de uma medida tão radical.

Detetive Senior - Então está a dizer que tomou a decisão correta naquele tempo? É essa a sua conclusão, Inspetora Tsunemori?

Detetive - Sim. O seu coeficiente criminal estava apenas temporariamente elevado. De facto, a terapia que recebeu após ter estado sob custódia está a correr bem e o seu psycho-pass está a recuperar. [ep. 2, 20:57-21:16]

Assim, mesmo através do uso de tecnologias convergentes ao dispor do sistema, numa organização societal em que praticamente não há espaço para o erro sem que este seja imediatamente identificado, os falsos positivos não deixam de ser uma realidade. Isto reforça um dos princípios da life-course criminology que defende ser de difícil identificação os falsos positivos e falsos negativos, devido à impossibilidade de antever 
comportamentos anti-sociais contínuos (Sampson e Laub, 2001). E que põe em causa, igualmente, um sistema que se baseie na atuação e consequente rotulação sobre e de um indivíduo que não agiu de forma delinquente e/ou criminal.

Detetive - Então disparava sobre uma vítima que ainda
não cometeu um crime? Não consigo aceitar isso! [ep. 1, 18:56]

Nesta sequência, outros produtos culturais, em particular Brave New World apresentaram ao leitor uma realidade social que valorizava a homogeneidade e a previsão de ações em que as ações de manipulação psicológica e condicionamento clássico serviram, quer para promover a ordem vigente, mas sobretudo para rotular o criminoso, mesmo quando este não tinha ainda agido criminalmente, promovendo falsos positivos.

\subsection{Tipo de fatores explicativos do envolvimento criminal dos indivíduos}

Os fatores explicativos avançados para o envolvimento criminal são igualmente reconfigurados à luz da observação totalitária dos estados e comportamentos dos indivíduos pertencentes à organização societal do Psycho-Pass.

Estando todos os domínios sociais sobre a alçada do sistema Sibyl, que determina o que é mais satisfatório para que cada indivíduo possa alcançar a felicidade de acordo com as suas características, os fatores explicativos tradicionais para o envolvimento criminal não são aqui identificados do mesmo modo.

O próprio sistema funciona como um fator explicativo por ser o elemento espoletador de alterações ao nível de todas as organizações sociais e fontes de socialização do indivíduo, como vimos no ponto anterior. Como é o sistema Sibyl que determina, por exemplo, se um indivíduo pode ter um emprego, que tipo de emprego, quanto deve auferir, se pode casar e/ou constituir família, entre outros elementos, é o próprio sistema que o poderá, no limite, forçar a recorrer ao crime.

Um outro aspeto importante a este nível é o que a série identifica como psycho-hazard, isto é, a possibilidade de a atividade criminosa se tornar contagiosa e afetar coletivamente a HUE dos indivíduos.

Cão de caça - Temos de nos despachar e decidir isto ou será o fim da refém.

Detetive - Psycho-hazard?

Cão de caça - Sim. Um coeficiente criminal pode ser contagioso. Os jovens de agora não são tolerantes contra o stress e são facilmente afetados por surtos e compulsões violentas. Pode acontecer a cada um de nós. [ep. $1,15: 56-16: 22]$ 
A função dos agentes passa por evitar pânicos morais, distúrbios da ordem, ou ações que aumentem a média de stress dos indivíduos. No primeiro episódio é apresentada uma vítima de rapto e violação que, por força das circunstâncias, aumenta o seu nível de stress, como apresentado no ponto anterior. Os agentes de segurança e os enforcers recebem ordem para utilização de força letal junto do agressor e junto da vítima. Para além disso, os próprios detetives são aconselhados a não criarem empatia com os enforcers pois, desse modo, podem desenvolver o mesmo tipo de coeficiente criminal. A identificação com o estilo de vida de um criminoso, as aprendizagens das normas e condutas percecionadas como criminais como sendo normativa, porque compreendidas, levariam igualmente ao contágio.

Cão de caça - Penso que é o melhor para si. Perceber o Kogami (ou qualquer outro cão de caça) significa que tem de ver as coisas como o Kogami vê e pensar como o Kogami pensa. Se for capaz de fazer isso, então o seu número no psycho-pass será o mesmo do Kogami. Quando olha por muito tempo para o abismo, o abismo também olha para si. [ep. 3, 04:39-05:16]

Dois dos mecanismos fundamentais apontados por Elder (2001) como sendo transformadores das trajetórias dos indivíduos e que podem levar à prática delinquente ou criminal são o tempo social e as vidas interdependentes. Esta situação em particular, assim como a primeira identificada neste ponto, remetem-nos imediatamente para estes mecanismos, e muito em particular para o segundo. As relações sociais, sejam elas voluntárias ou involuntárias, interferem com a trajetória do indivíduo. A interação entre o indivíduo e o seu mundo social ao longo de todo o seu ciclo de vida, com a família, amigos, colegas de trabalho ou mesmo desconhecidos afeta de forma irremediável o curso de vida e, no limite, o envolvimento criminal.

\section{Considerações finais}

Este exercício de reflexão permite-nos estabelecer pontes de contacto entre produtos culturais, tecnologias convergentes e crime. A partir do Psycho-Pass analisa-se o modo como as tecnologias convergentes, assentes em regimes de predictive thinking, enformam toda uma organização societal, conferindo-lhe uma determinada configuração em termos de definição do crime e atuação face às práticas criminais. $\mathrm{O}$ anime apresenta uma sociedade no qual um sistema tecnológico de conversão de dados moldou as técnicas de controlo social e, consequentemente, o comportamento humano. Mais que um mero exercício de imaginação ou de reflexão enquadrado nos moldes da ficção científica, 
Psycho-Pass recorre a tecnologias e aplicações em fase embrionária no presente e demonstrou o seu potencial num futuro. E procedeu a este enquadramento através da prática criminal.

Ao centrar-se narrativamente na esfera do (pós) cyberpunk, o anime levanta dúvidas sobre o tipo de desenvolvimento social existente. Se, por um lado, o controlo é omnipresente numa sociedade distópica, por outro, apresenta um crescimento económico pujante e uma paz social vigente. Ao assumir que as suas personagens conhecem as diversas obras que refletiram sobre sistemas de vigilância e controlo totalitário, tais como 1984 e Brave New World, constrói a narrativa na constatação que os indivíduos aceitaram, interiorizaram e normalizaram as formas de controlo do sistema Sibyl.

O facto de o humano transcender a sua condição como espécie, incorporando novas formas, em particular cyborgs e transhumanos, não impede que o sistema Sibyl seja capaz de ler, processar e analisar as formas de informação biométrica, estando os novos estados da evolução humana também sob a sua alçada e controlo. Portanto, o sistema criado por Sibyl reduziu os agentes policiais a meros recetores de ordens e utilizadores de dispositivos. A introdução da personagem da detetive Akane apresenta, por isso, um espaço de reflexão: alguém que defende a ordem e a sua implementação, mas que problematiza a sua aplicação e acrescenta uma esfera de humanismo à vertente burocrática tecnológica.

É precisamente este elemento humanizador da série que vem colocar em causa o próprio predictive system, quando se opõe deliberadamente às concepções e diretrizes do sistema Sibyl, mostrando que o mesmo, apesar de ser preciso e de prever o comportamento criminal, antes deste acontecer, também falha. Esta falha na análise do sistema, à luz das teorias do curso de vida, deve-se à mutabilidade das trajetórias de vida dos indivíduos, que estão dependentes de eventos de vida, do tempo social ou das vidas interdependentes, como o episódio relatado acima tão bem demonstra. Para além disso, evidencia-se a forma como o sistema Sibyl cria as condições - gerando a self-fulfiling prophecy - para que determinados indivíduos sejam identificados como criminosos, não havendo numa organização social indivíduos pré-determinados como criminosos. Assim, esta personagem incorpora os pressupostos da impossibilidade de antever comportamentos anti-sociais contínuos, assim como põe em causa um sistema que se baseie na rotulação de um indivíduo que não agiu de forma delinquente e/ou criminal. Os binómios típicos do cyberpunk estão bem presentes: high tech, low life, racional e irracional, controlo e liberdade. Psycho-Pass deixa uma pista de reflexão final: mesmo após o sucesso do sistema Sibyl através da aplicação de um sistema inteiramente racional, não elimina a ação não-racional. Quando se implementa uma norma, existe alguém para a quebrar: "O nosso trabalho é feito de coisas 'irrazoáveis' em primeiro lugar. O que uma pessoa 
pensa, o que deseja... Vivemos num tempo em que tudo o que está na mente de uma pessoa é tornado transparente por máquinas e, apesar de tudo, há milhares de pessoas que detestam, enganam ou tentam enganar os outros. Se isso não é ‘irrazoável', o que mais lhe poderás chamar?” [ep. 1, 12:59-13:20].

\section{Referências bibliográficas}

ALLISON, A. (2009), "The Cool Brand, Affective Activism and Japanese Youth", Theory, Culture \& Society, 26(2-3), 89-111. http://doi.org/10.1177/0263276409103118.

ALTHUSSER, L. (2014), On the Reproduction of Capitalism: Ideology and Ideological State Apparatuses, Edinburgh: Hewer Text. http://doi.org/10.1017/CBO9781107415324.004.

APPADURAI, A. (1986), The Social Life of Things. Cambridge: Cambridge University Press.

BALL, P. (2010), “Making Life: A Comment on "Playing God in Frankenstein's Footsteps: Synthetic Biology and the Meaning of Life" in Henk van den Belt (2009), Nanoethics, 4, 129-132. http://doi.org/10.1007/s11569-010-0091-x.

BOSTROM, N. (2005), “A History of Transhumanist Thought", Journal of Evolution and Technology, 14(1), 1-25.

BOWMAN, D. M., e HODGE, G. A. (2007), "Nanotechnology and Public Interest Dialogue: Some International Observations", Bulletin of Science, Technology \& Society, 27(2), 118132. http://doi.org/10.1177/0270467606298216.

BOWMAN, D. M., HODGE, G. A., e BINKS, P. (2007), “Are We Really the Prey? Nanotechnology as Science and Science Fiction”, Bulletin of Science, Technology \& Society, 27(6), 435-445. http://doi.org/10.1177/0270467607308282.

BUTRYN, T. M., e MASUCCI, M. A. (2009), "Transversing the Matrix: Cyborg Athletes, Technology and the Enviroment", Journal of Sports \& Social Issues, 33(3), 285-307.

COENEN, C. (2014), "NanoEthics Seven Years On", NanoEthics, 8(2), 117-119. http://doi. org/10.1007/s11569-014-0208-8.

CONDRY, I. (2009), “Anime Creativity: Characters and Premises in the Quest for Cool Japan”, Theory, Culture \& Society, 26(2-3), 139-163. http://doi.org/10.1177/0263276409103111.

DAWESAR, A. (2013), Life in the "Digital Now." United Kingdom. Retrieved from https://www. ted.com/talks/abha_dawesar_life_in_the_digital_now?language=en.

DEWAN, S. (2015), "Judges Replacing Conjecture With Formula for Bail”, New York Times. Retrieved from https://www.nytimes.com/2015/06/27/us/turning-the-granting-of-bail-into-a-science.html.

DUARTE, B. N. (2014), "Entangled Agencies: New Individual Practices of Human-Technology Hybridism Through Body Hacking", NanoEthics, 8(3), 275-285. http://doi.org/10.1007/ s11569-014-0204-z.

DUBIEL, H. (2011), "What is "Narrative Bioethics"”, Frontiers in Integrative Neuroscience, 5, 10. http://doi.org/10.3389/fnint.2011.00010.

ELDER, G. H. (1985), "Perspectives on the life-course" in G. H. Elder (Ed.), Life-course dynamics. Ithaca, NY: Cornell University Press.

ELDER, G. H., GIMBEL, C., e IVIE, R. (1991), “Turning points in life: The case of military service and war", Military Psychology, 3, 215-231.

FRANKLIN, S. (2006), "The Cyborg Embryo: Our Path to Transbiology”, Theory, Culture \& Society, 23(1997), 167-187. http://doi.org/10.1177/0263276406069230.

GANE, N., e HARAWAY, D. (2006), "When we have never been human, what is to be done? Interview with Donna Haraway”, 23, 135-158. http://doi.org/10.1177/0263276406069228. 
HARAWAY, D. (1985), "Manifesto for cyborgs : Science, Technology , and Socialist-Feminism in the 1980s", Socialist Reviex, 80(80), 65-108. http://doi.org/10.1007/978-1-4020-3803-7_4.

IHDE, D. (2008), “Aging: I don't want to be a cyborg!", Phenomenology and the Cognitive Sciences, 7(July), 397-404. http://doi.org/10.1007/s11097-008-9096-0.

ITO, M. (2006), "The Gender Dynamics of the Japanese Media Mix" in Girls " $n$ " Games Workshop and Conference. Los Angeles.

JAPAN TODAY. (2017), "Kyoto police set up system to predict when and where crimes will happen”, Japan Today. Retrieved from https://japantoday.com/category/crime/ kyoto-police-set-up-system-to-predict-when-and-where-crimes-will-happen

JONES, R. (2007), Soft Machines: Nanotechnology and Life. New York, Oxford University Press.

KIRBY, D. A. (2008), “The Devil in Our DNA: A Brief History of Eugenics”, Science Fiction Films, 1(1), 83-108.

KYVSGAARD, B. (2003), The Criminal Career: The Danish Longitudinal Study, Cambridge, Cambridge University Press.

LAUB, S. P. (2004), Crime Prevention: Approaches, Practices and Evaluations. Fifth edition. Newark, NJ: Lexis Nexis.

LATOUR, B. (2008), “It's development, stupid!” or: How to Modernize Modernization”, Postenvironmentalism (pp. 1-13). MIT Press.

LeBLANC, M. (2006), "Self-control and social control of deviant behavior in context: development and interactions along the life course" in Per-Olof H. Wikstrom and R. J. Sampson (Eds.), The Explanation of Crime: Context, Mechanisms, and Development. Cambridge, Cambridge University Press, pp. 195-242.

LI, Y., e KUO, C. C. J. (2003), Video Content Analysis Using Multimodal Information: For Movie Content Extraction, Indexing and Representation.

MURI, A. (2003), "Of Shit and the Soul: Tropes of Cybernetic Disembodiment in Contemporary Culture", Body \& Society, 9(3), 73-92. http://doi.org/10.1177/1357034X030093005.

OLIVARES, L. (2014), "Hacking the Body and Posthumanist Transbecoming: 10,000 Generations Later as the mestizaje of Speculative Cyborg Feminism and Significant Otherness”, NanoEthics, 8(3), 287-297. http://doi.org/10.1007/s11569-014-0203-0.

OTT, I., e PAPILLOUD, C. (2007), "Converging Institutions : Shaping Relationships Between Nanotechnologies, Economy, and Society”, Bulletin of Science Technology \& Society, 27, 455. http://doi.org/10.1177/0270467607309764

PARK, E. (2014), "Ethical Issues in Cyborg Technology: Diversity and Inclusion", NanoEthics, 8(3), 303-306. http://doi.org/10.1007/s11569-014-0206-x

PIQUERO, A. R., e MAZEROLLE, P. (2001), Life-Course Criminology - Contemporary and classic readings, Ontario, The Wadsworth.

RAE, G. (2014), “The Philosophical Roots of Donna Haraway's Cyborg Imagery: Descartes and Heidegger Through Latour, Derrida, and Agamben”, Human Studies, 37, 505-528. http:// doi.org/10.1007/s10746-014-9327-z

RAPOPORT, M. (2013), "Being a body or having one: Automated domestic technologies and corporeality", AI and Society, 28, 209-218. http://doi.org/10.1007/s00146-012-0406-2

RIBEIRO, R. (2011), A Europa na Identidade Nacional, Porto, Edições Afrontamento.

ROCO, M. C. (2007), "Convergence and Integration" in L. E. Foster (Ed.), Nanotechnology Science, Innovation and Opportunity, New Jersey, Prentice Hall, pp. 225-232.

ROSE, G. (2007), Visual Methodologies: An Introduction to the Interpretation of Visual Materials, London, SAGE Publications.

RUTTER, M., e RUTTER, M. (1993), Developing minds: challenge and continuity across the life-span, New York, Basic Books. 
SAMPSON, R. J, e LAUB, J. H. (1993), Crime in the Making - Pathways and turning points through life, Cambridge, Harvard University Press.

SAMPSON, R. J., e LAUB, J. H. (2001), "Crime and Deviance in the Life Course" in A. Piquero and P. Mazerolle (Ed.), Life Course Criminology - Contemporary and Classic Readings. Stamford, Wadsworth Thomson Learning, pp. 21-42.

SAVAGE, J. (2009), The Development of Persistent Criminality, Oxford, New York, Oxford University Press.

SHIELDS, R. (2006), "Flanerie for Cyborgs", Theory, Culture \& Society, 23(7-8), 209-220. http://doi.org/10.1177/0263276406069233

THORNBERRY, T. P. (1997), "Introduction: Some advantages of developmental and life-course perspectives for the study of crime and delinquency" in T. P. Thornberry (Ed.), Developmental theories of crime and delinquency: Advances in criminological theory, New Brunswick, Transaction Publishers.

VAN DER LAAN, J. M. (2010), "Frankenstein as Science Fiction and Fact”, Bulletin of Science, Technology \& Society, 30(4), 298-304. http://doi.org/10.1177/0270467610373822. 